
- ACT Events
- Dialogue
- NSW Events
- Queensland Events
- $\underline{\text { SA Events }}$
- Tasmania Events
- Victoria Events
- WA Events
- Past Events
- Links

- Youth and Community

- Youth Engagement

- Internships

- Nygh Internship

- Euan Crone Asian Awareness Scholarship

- Study Tours

- Volunteers

- Friends of the AIIA

- Partners

- News and Media

- News

- Media Library

- About Us

- Locations

- About the AIIA

- Structure

- Our People

- Fellows of the AIIA

- Libraries

- Venue Hire

- Chatham House Rule

- Contact Us

$\underline{\text { Home }}>\underline{\text { Australian Outlook }}>\underline{\text { Reading Room }}>$ Will China Dominate the 21st Century? « Go back

\title{
Will China Dominate the 21st Century?
}

By reviewer Oliver Stuenkel

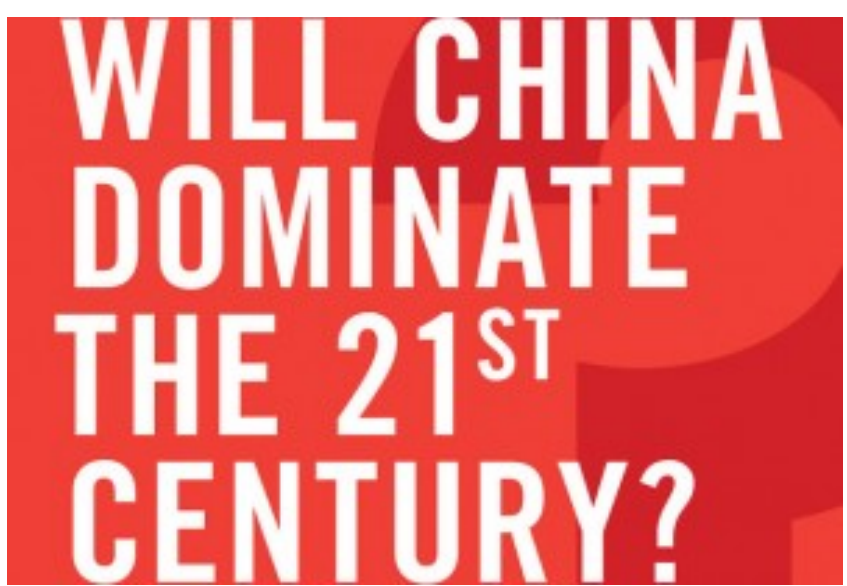


Will China dominate the 21 st century? Jonathan Fenby, prolific author and long-term China-watcher, responds with an emphatic 'no'. In his new book, he provides an exhaustive list of the many challenges policy-makers in Beijing will face over the coming years. He believes that many foreigners and Chinese alike have bought into a flawed narrative according to which China's return to the global centre is a natural and effortless process. Just like emperors with a mandate from heaven, Fenby writes, today's Communist Party leaders are often ascribed with an almost supernatural capacity to steer their nation of 1.35 billion people towards prosperity.

Fenby is highly knowledgeable about China and this is his eighth book on the topic. While the author recognises that China has made astonishing progress over the past three decades, his analysis leaves no doubt that he regards long-term growth projections as hopelessly optimistic.

To most readers, used to more positive projections, the author may come across as overly critical of China. Page after page is filled with horrific statistics about pollution, food poisoning and corruption. While the numbers marshalled are indeed impressive, the author can be criticised for failing to put them in perspective: for example, how does environmental damage affect Chinese citizens' lives in comparison to those in India or Indonesia? In the same way, the text is littered with anecdotes that are hardly solid evidence to identify a trend: for example, he cites a school girl who, in a television interview, says she dreams of becoming a corrupt official yet such cases can be found in any country in the world (except perhaps Singapore and Norway). A major train crash in 2011 is described as 'a stark reminder that, while the PRC can buy or copy foreign technology, it also has to be able to operate it safely,' yet train crashes are no more frequent in China than in other developing countries. The 2011 crash can be seen more as a symptom of the government's pressure to fulfil unrealistic goals rather than its incapacity to adopt technology.

While cautionary tales are indeed necessary when analysing China's future, Fenby's analysis is not always balanced, particularly towards the end of the book. Critical observations that focus on issues that say little about China or its society can sound like some sort of personal vendetta:

Even sources of China's pride and joy have their hollow aspects. At the opening of the Beijing Olympics, the girl singer was dubbed since the real performer was regarded as insufficiently goodlooking and all the 56 children who paraded as representatives of ethnic minorities were Han dressed in colourful disguise.

Fenby's analysis also suffers from a lack of sources. He argues that Chinese commentators say their country deserves equality with the United States; I would argue that most policy-makers in China are, in fact, more modest about China's global role and unwilling to accept a G2-scenario. The majority of those predicting a Chinese-dominated 21st Century are western; many Chinese officials regard this as a strategy to force China to assume more global responsibilities.

Fenby is certainly right to argue that it is far from assured whether China can keep up its current growth trajectory and circumvent the countless economic, environmental, political, social and demographic challenges it faces. Yet his book ends up being too one-sided to have a lasting impact on the debate.

Jonathan Fenby, Will China Dominate the 21st Century? Polity, Cambridge, 2014

Dr Oliver Stuenkel is an Assistant Professor of International Relations at the Getulio Vargas

Foundation (FGV) in São Paulo, Brazil. His areas of academic endeavour focuses on rising powers; specifically on Brazil's, India's and China's foreign policy and their impact on global governance.

Published July 1, 2015

Share $\quad$ Gweet Share

